\title{
The diversity of sex steroid action: the role of micro-RNAs and FOXO transcription factors in cycling endometrium and cancer
}

\author{
Eric W-F Lam ${ }^{1}$, Kunal Shah ${ }^{2}$ and Jan J Brosens ${ }^{2}$ \\ ${ }^{1}$ Cancer Research-UK Laboratories, Division of Cancer and ${ }^{2}$ Institute of Reproductive and Developmental Biology, Department of Surgery and Cancer, Imperial \\ College London, Hammersmith Hospital Campus, Du Cane Road, London W12 0NN, UK \\ (Correspondence should be addressed to E W-F Lam; Email: eric.lam@imperial.ac.uk)
}

\begin{abstract}
The rise and fall in ovarian oestrogen and progesterone production orchestrates a series of events that are indispensable for reproduction, including ovulation, implantation, decidualisation and menstruation. In the uterus, these events involve extensive tissue remodelling, characterised by waves of endometrial cell proliferation, differentiation, recruitment of inflammatory cells, apoptosis, tissue breakdown, menstruation and regeneration. The ability of ovarian hormones to trigger such diverse physiological responses is foremost dependent upon interaction of activated steroid receptors with specific transcription factors, such as Forkhead box class O (FOXO) proteins, involved in cell fate decisions. Furthermore,

micro-RNAs (miRNAs), small non-coding RNAs that function as posttranscriptional regulators of gene expression, have emerged as a major regulator system of steroid hormone responses in the female reproductive tract. Consequently, increasing evidence shows that deregulated uterine miRNA expression underpins a spectrum of common reproductive disorders, ranging from implantation failure to endometriosis. Furthermore, by targeting FOXO transcription factors and other key regulators of tissue homeostasis, oncogenic endometrial miRNAs promote tumourigenesis and cancer progression.

Journal of Endocrinology (2012) 212, 13-25
\end{abstract}

\section{Introduction}

Micro-RNAs (miRNAs) are small non-coding RNAs, $\sim 22$ nucleotides in length, which function as posttranscriptional regulators of gene expression. To date, almost 1000 human miRNAs have been identified and validated (Griffiths-Jones 2010). However, in silico studies suggest that there might be as many as tens of thousands potential miRNA species in mammalian cells (Miranda et al. 2006), and it has been predicted that at least $60 \%$ of all transcripts are targeted by miRNAs (Friedman et al. 2009). MiRNAs are essential for normal mammalian development, determining cell identity and fate and regulating diverse biological processes including cell proliferation, metabolism, differentiation and apoptosis. Conversely, miRNAs are also increasingly implicated in the pathogenesis of numerous benign and malignant diseases, including hormone-dependent endometrial, ovarian and breast cancers. In fact, different cancers have distinct

This paper is one of three papers that form part of a thematic review section on the diversity of sex steroid action. The Guest Editor for this section was Matti Poutanen, University of Turku, Finland.
miRNA expression signatures, referred to as oncomiRs, that contribute towards cancer initiation and progression by enhancing or inhibiting the expression of oncogenes and tumour suppressors respectively.

The magnitude of hormone-dependent tissue remodelling in the uterus is unsurpassed in the human body, characterised by $\sim 400$ cycles of endometrial cell proliferation, differentiation, menstrual shedding and regeneration. Although sex steroid hormones and activation of their cognate nuclear receptors are the key regulators in cyclic tissue remodelling of the endometrium, a host of interacting transcriptional partners, including Forkhead box class O1 (FOXO1; Christian et al. 2002c), signal transducers and activators of transcription 5 (STAT5) and CCAAT/enhancer-binding protein $\beta$ (C/EBP $\beta$ ) (Christian et al. 2002a,b), also play a vital role in determining and fine-tuning the transcriptional responses in target cells. Furthermore, certain factors have emerged as important for safeguarding genomic integrity and tissue homeostasis during these rapid cycles of intense tissue remodelling. Among these factors are members of the FOXO family of transcription factors. FOXO proteins, functioning downstream of the phosphoinositol-3-kinase (PI3K)/AKT 
oncogenic signalling pathway, are central to a diversity of cellular functions, including cell proliferation, apoptosis, differentiation and resistance to oxidative stress and DNA damage (Lam et al. 2006, Reedquist et al. 2006, Huang \& Tindall 2007, Myatt \& Lam 2007, Arden 2008, Burgering 2008, Calnan \& Brunet 2008, Fu \& Tindall 2008, Gomes et al. 2008, Ho et al. 2008, Maiese et al. 2008b).

The human FOXO family consists of four members: FOXO1 (also known as FKHR), FOXO3 (FKHRL1), FOXO4 (AFX or Mllt7) and FOXO6. Their expression is highly regulated depending on the tissue type and developmental stage (Maiese et al. 2008a). In the human uterus, for example, FOXO1 is expressed in the endometrial stroma but only following differentiation of stromal fibroblasts into decidual cells during the mid-secretory phase of the cycle, whereas in the epithelial compartment, it is expressed constitutively throughout the menstrual cycle (Christian et al. 2002c, Goto et al. 2008). FOXO3a expression, by contrast, is downregulated upon decidualisation of endometrial stromal cells (Kajihara et al. 2006). Although FOXO4 transcripts are detectable in human endometrium, evidence of expression at protein level is yet lacking (Kajihara et al. 2006). FOXO6 expression is thought to be restricted to adult brain tissues (Jacobs et al. 2003). It is the ability of FOXOs to control opposing gene networks which are implicated in cell survival, differentiation and cell death responses, which render them key regulators of endometrial homeostasis. Consequently, loss of FOXO disables the ability of cells to arrest at key checkpoints, thereby facilitating tumour development. The notion that FOXO proteins are indeed bona fide tumour suppressors is supported by animal studies demonstrating that loss of FOXO activity leads to the development of pre-cancer conditions, including thymic lymphomas and haemangiomas (Paik et al. 2007), as well as accelerating Myc-driven lymphomagenesis (Bouchard et al. 2007). In this review, we summarise the mechanism of miRNA biogenesis and highlight the role of miRNA and FOXO transcription factors in modulating the hormonal responses in the endometrium. We also discuss how deregulated miRNA expression impacts on FOXO function, disrupts endometrial tissue homeostasis and contributes to the malignant transformation of the endometrium.

\section{miRNA biosynthesis and mechanism of action}

The biogenesis of miRNAs is a multi-stage process. It commences in the nucleus where the miRNA genes are first transcribed by RNA polymerase II, or sometimes by RNA polymerase III, into long primary miRNA transcripts (pri-miRNAs; Schwarz et al. 2003, Du \& Zamore 2005, 2007). These capped and polyadenylated pri-miRNAs contain a hairpin stem of $33 \mathrm{bp}$, a terminal loop and two single-stranded flanking regions (Cai et al. 2004). Many miRNA gene loci are clustered and are, therefore, transcribed together and encoded in polycistronic transcripts
(Tanzer \& Stadler 2004). The pri-miRNAs are then processed in the nucleus by a complex consisting of the RNase III enzyme, DROSHA, as well as the DiGeorge syndrome critical region 8 protein (DGCR8; Han et al. 2004). The DROSHA/DGCR8 containing the complex truncates the flanking segments and a $<11 \mathrm{bp}$ stem region, converting the pri-miRNAs into precursor miRNAs (pre-miRNAs; Fig. 1), which are about $70 \mathrm{bp}$ long hairpin RNAs with $2 \mathrm{bp}$ overhanging at the $3^{\prime}$-end. Pre-miRNAs can also be generated by a DROSHA/DGCR8-independent processing pathway, whereas pre-miRNAs are derived directly from introns through the action of mRNA splicing mechanisms (Lin et al. 2005, Ying \& Lin 2006). Either way, pre-miRNAs are then transported by the exportin-5/RanGTP complex from the nucleus to the cytoplasm (Fig. 1), where they are processed by RNase III enzyme DICER (Fig. 1; Filipowicz et al. 2008, Chekulaeva \& Filipowicz 2009). Dicer then cleaves pre-miRNAs into $21-25$ bp long miRNA/complementary miRNA (miRNA ${ }^{\star}$ ) duplexes. The miRNA/miRNA ${ }^{\star}$ duplex is essential for the assembly of miRNA-induced silencing complexes (RISC), which is made up primarily of Argonaute (Ago) proteins as the core catalytic components. During the miRISC assembly, the miRNA strand of the duplex is loaded into the (RISC) complex, whereas the other miRNA` strand is discarded. With the mature miRNA as a guide, the miRNA-RISC complex hybridises to complementary nucleotide sequences on target mRNAs. MiRNAs bind to target sites frequently located in the $3^{\prime}$-untranslated region (UTR) of the target mRNA but can also sometimes be found within the $5^{\prime}$-UTR or coding region. There has been much debate about how exactly miRNAs affect protein expression levels. Early studies in Caenorhabditis elegans concluded that miRNAs decrease translational output with little effect on target mRNA levels. Other studies involving microarray analysis and overexpression of particular miRNAs indicated that mRNA levels of predicted targets were reduced by miRNA activity. A recent study provided further evidence that miRNAs influence protein output mainly by destabilising target transcripts rather than just repressing their translation (Guo et al. 2010). Furthermore, emerging evidence suggests that primary and pre-miRNAs can also potentially interact with target mRNAs and repress gene expression (Trujillo et al. 2010). In particular, miRNA biosynthesis is influenced by steroid hormones. For example, DROSHA has been shown to interact with the activated oestrogen receptor (ER). This inhibited the maturation of a subset of pri-miRNAs and, consequently, the mRNA targets of these miRNAs were more abundantly expressed (Yamagata et al. 2009).

\section{miRNAs and endometrial function}

The endometrial remodelling in response to the rise and fall in ovarian oestradiol and progesterone production is exquisitely regulated by coordinated activation of the ER 


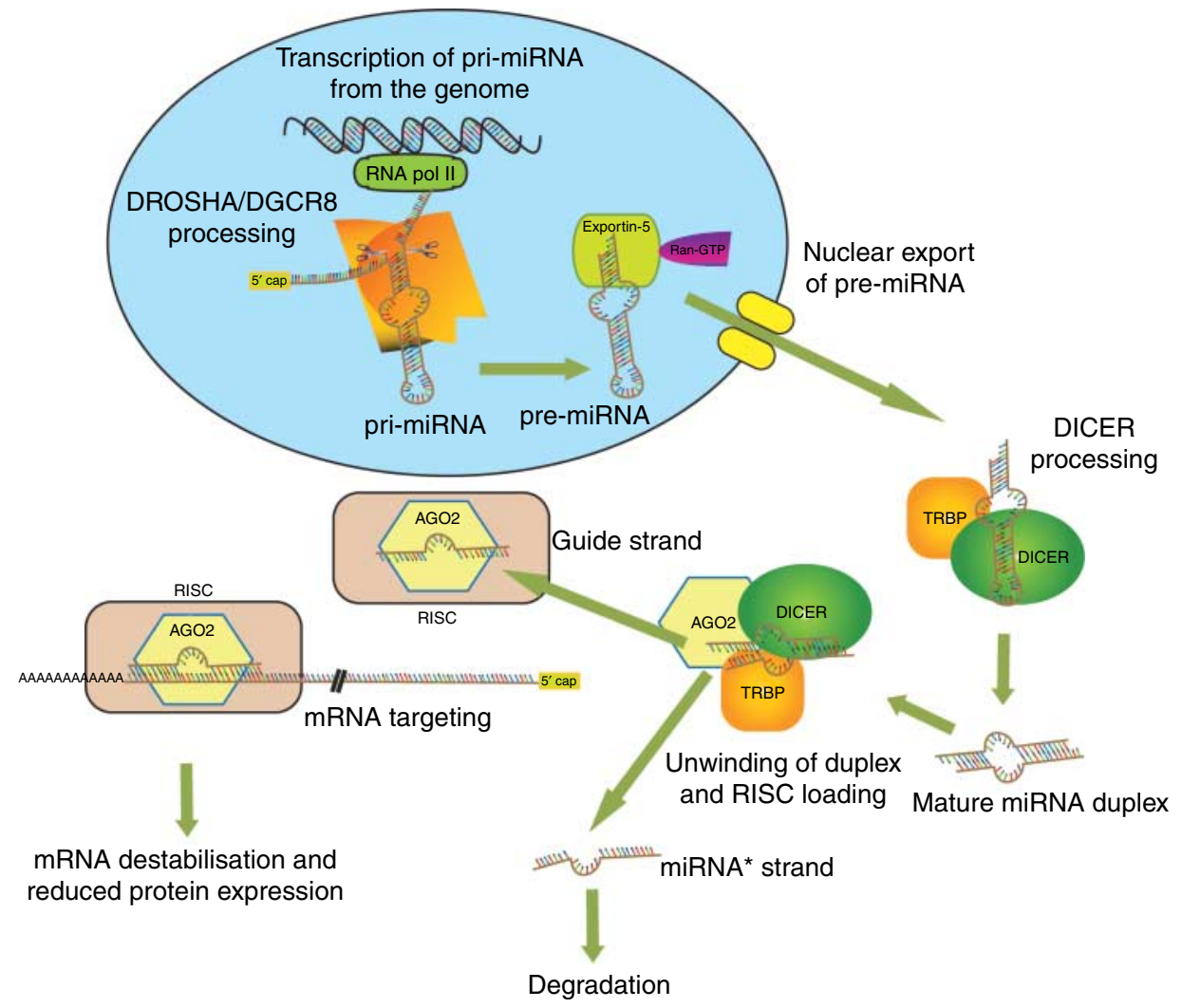

Figure 1 Biogenesis of miRNAs. Micro-RNA genes are transcribed from the genome by RNA polymerase II to generate primary transcripts (pri-miRNAs) that are $>1 \mathrm{~kb}$ in length. The microprocessor complex consisting of DROSHA and DGCR8 then processes the pri-miRNAs to release $\sim 70$ nucleotide stem-loop precursor miRNAs (pre-miRNAs). The re-miRNA molecules are exported from the nucleus to the cytoplasm by exportin-5 and Ran-GTP. To generate functional miRNAs, pre-miRNAs are further processed in the cytoplasm by Dicer, which dimerises with TRBP. DICER removes the loop region to generate a mature miRNA/miRNA* duplex. Unwinding of the duplex coincides with loading of one strand (the guide strand) onto the RNA-induced silencing complex (RISC), whereas the other (passenger) strand is discarded. The miRNA-loaded RISC also contains Argonaute (AGO) proteins, of which AGO2 has ribonuclease activity, and specific mRNA molecules can be targeted by RISC due to the ability of the guide strand to bind complementary sites in the 3'-UTR of mRNAs. This targeting has a negative impact on mRNA translation mediated mainly by destabilisation of the mRNA.

and progesterone receptor (PR) respectively, members of the superfamily of ligand-dependent nuclear transcription factors. Although ER and PR are expressed in both the epithelial and the stromal compartments, it should be observed that stromal cells also abundantly express androgen and glucocorticoid receptors ( $\mathrm{AR}$ and $\mathrm{GR}$ respectively). AR expression resembles that of $\mathrm{PR}$, with the highest levels occurring during the proliferative phase, followed by declining receptor levels throughout the secretory phase of the cycle (Cloke et al. 2010). In contrast, GR expression in the stromal compartment has been reported to be fairly constant across the cycle (McDonald et al. 2006).

Ovarian oestradiol induces the ordered growth of the endometrium, whereas the postovulatory rise in progesterone levels controls differentiation of this tissue in preparation for embryo implantation. This differentiation process, termed 'decidualisation', is characterised first by the secretory transformation of the endometrial glands, followed by an influx of immune cells, including macrophages and uterine natural killer cells, angiogenesis and transformation of endometrial stromal cells into specialised epitheloid decidual cells (Brosens et al. 2002). In the absence of pregnancy, declining progesterone levels trigger a switch in the secretory repertoire of decidual stromal cells, now characterised by the expression of pro-inflammatory cytokines, chemokines and matrix metalloproteinases, which activate a sequence of events leading to tissue breakdown of the superficial endometrial layer, focal bleeding and menstrual shedding (Brosens \& Gellersen 2006).

Compelling evidence has emerged to indicate that the ability of progesterone to counteract the proliferative effects of oestrogen involves expression of miRNAs that repress genes implicated in cell cycle progression. Profiling studies of the endometrium revealed 12 distinct miRNAs (miR-29b, miR-29c, miR-30b, miR-30d, miR-31, miR-193a-3p, miR-203, miR-204, miR-200c, miR-210, miR-582-5p and miR-345), whose expression was significantly upregulated in the secretory compared with the proliferative phase of 
the cycle, when progesterone exerts its function. These miRNAs are predicted to repress the expression of many cell cycle regulators, including cyclins, cyclin-dependent kinases and the transcription factor E2F3, a validated target of miR-210 (Kuokkanen et al. 2010). Another microarray study identified 32 miRNAs differentially expressed between isolated human endometrial stromal and glandular epithelial cells (Pan et al. 2007). Furthermore, treatment of these primary cultures with synthetic steroids $17 \beta$-oestradiol and medroxyprogesterone acetate differentially regulated the expression of miR-20a, miR-21 and miR-26a, which was partly reversed following co-treatment with the pure antioestrogen ICI 182780 (Pan et al. 2007). These observations highlight that miRNA expression in both the stromal and the epithelial compartments of the endometrium is under hormonal control.

Expression of DICER and the AGO proteins, which make up the RISC complex, is maintained at high levels in the pregnant uterus, at least in the mouse (Chakrabarty et al. 2007, Hu et al. 2008). Furthermore, 32 miRNA species were found to be upregulated during early pregnancy in the mouse (Chakrabarty et al. 2007). The expression of miR-101 and miR-199^, induced by oestradiol, was found to enhance the expression of cyclooxygenase-2, an enzyme indispensable for implantation in mice (Chakrabarty et al. 2007). Additional analysis identified 13 miRNAs upregulated at implantation sites compared with inter-implantation sites (Hu et al. 2008), indicating that the spatiotemporal expression of uterine miRNA is regulated by embryonic signals (Chakrabarty et al. 2007). Interestingly, placenta-specific miRNAs have been detected in the maternal circulation during pregnancy (Luo et al. 2009). Furthermore, the BeWo trophoblast cell line was shown to secrete miRNA in exosomes, raising the possibility that placental miRNAs are taken up at the foetalmaternal interface by decidual or immune cells with functional consequences on gene expression. The expression of miRNAs has also been studied in human endometrial stromal cells that were decidualised in culture for 4 days. Interestingly, out of 49 miRNAs regulated twofold or more, two-thirds were reported to be downregulated in decidualising cells (Qian et al. 2009). However, these results should be interpreted with caution as decidualising endometrial cells acquire a highly secretory phenotype, suggesting that miRNAs may be produced primarily for export. It should also be observed that several miRNA species can regulate ER and PR expression (Pandey \& Picard 2010), and the experimentally validated miRNAs that can control ER expression include miR-18ab, miR-19, miR-22, $\mathrm{miR}-26 \mathrm{ab} / 1297$, miR-181, $\mathrm{miR}-206$ and miR-222/221 (Adam et al. 2009, Castellano et al. 2009, Liu et al. 2009, Pandey \& Picard 2009, Di Leva et al. 2010). PR expression has also been found to be modulated by miR-181 and miR-26ab/1297 (Castellano et al. 2009). However, the expression of these species and their function in the endometrium has not been examined systematically.

\section{Role of miRs in ovarian hormone production}

Endometrial function is also indirectly regulated by miRNA involved in modulating ovarian steroidogenesis. In the ovary, the granulosa and thecal cells support the growth and maturation of the oocytes as well as secreting hormones, including progesterone, testosterone and oestradiol to regulate the development of endometrium. Thus, miRNAs also regulate endometrial proliferation and development indirectly through modulating the ovarian development and hormone production. A number of ovarian-specific miRNAs have already been identified by miRNA profiling studies in mice (Choi et al. 2007, Ro et al. 2007, Mishima et al. 2008, Ahn et al. 2010). Of these, the miRNAs let-7a, miR-125b and miR-143 have also been confirmed to be negatively regulated by FSH in mouse granulosa cells of primary, secondary and antral follicles (Yao et al. 2009). In a similar human study, 212 specific miRNA species have been identified in the granulosa cells isolated from peri-ovulatory follicles, 13 of which are regulated by the LH (Fiedler et al. 2008). A genome-wide screen has identified both potential inhibitory and stimulatory miRNAs affecting the release of the major sex steroid hormones progesterone, testosterone and oestradiol in human ovarian cells, with 36,51 and 57 specific miRNAs decreasing and 10, 0 and 1 miRNAs increasing progesterone, testosterone and oestradiol production respectively (Sirotkin et al. 2009).

\section{Role of miRNAs in endometriosis}

As the expression of endometrial miRNAs is under hormonal control, and in turn modulates the cellular responses to steroid signalling, several investigators have focussed on their role in pelvic endometriosis, a common oestrogen-dependent reproductive disorder characterised by the presence of endometrial tissues outside the uterine cavity (Eskenazi \& Warner 1997). Endometriosis affects as many as $10 \%$ of all women of reproductive age and is a major cause of pelvic pain and conception delay. Microarray analyses have been employed to identify differentially expressed miRNAs in paired eutopic endometrium and ectopic lesions (Filigheddu et al. 2010, Teague et al. 2010). Although one study yielded 22 differentially expressed miRNAs and another 50 species, the validity of this approach is somewhat questionable, as endometriotic implants differ profoundly in architecture and cellular composition when compared with eutopic endometrium.

In recent years, abundant evidence has emerged to indicate that steroid hormone responses in eutopic endometrium are grossly perturbed in patients suffering from endometriosis. Microarray studies have been particularly informative to delineate the nature and magnitude of impaired endometrial gene expression in patients with endometriosis. For example, Kao et al. (2003) identified in excess of 200 dysregulated genes 
in mid-secretory biopsies from women with minimal or mild endometriosis compared with disease-free controls. A subsequent study showed that impaired gene expression in eutopic endometrium of patients with endometriosis encompasses the entire cycle, including the proliferative phase, although the most extensive perturbations were found in early secretory endometrium (Burney et al. 2007). Many of the dysregulated genes identified during this phase of the cycle are not only bona fide progesterone targets but the overall signature suggests a persistent proliferative phenotype of the endometrium. Interestingly, the perturbed gene expression in eutopic secretory endometrium of affected patients coincides with differential expression of several miRNA species (Burney et al. 2009). In particular, members of the miR-9 and miR-34 families (i.e. miR-9, miR-34b夫 and miR-34c$5 p)$ are downregulated in the endometrium from women with endometriosis compared with healthy individuals. The predicted targets of the miR-9 and miR-34 families include the cell-cycle regulator genes cyclin E1, cyclin E2, CDK4, $C D K 6$ and $C D C 25 A$ and the anti-apoptotic gene, BCL-2, which are also differentially expressed in endometrium from women with and without endometriosis.

\section{FOXO proteins: regulators of hormone-dependent cell fate}

FOXO transcription factors are at the centre of an emerging paradigm that links longevity, cell fate and tumour development. Like members of the p53 family of tumour suppressors, FOXO proteins have the innate ability to control distinct and opposing gene programs, leading to cell death or survival and differentiation. Although only partially understood, this contrasting behaviour of FOXO proteins is largely determined by specific and interrelated posttranslational modifications that dynamically respond to changes in growth factor, hormonal and environmental cues. Perhaps, the best characterised posttranslational modification of FOXO proteins involves inactivating phosphorylation by the $\mathrm{PI} 3 \mathrm{~K} / \mathrm{AKT}$ pathway in response to insulin and growth factor signalling. PI3K/AKT-dependent phosphorylation of FOXO proteins triggers their export from the nucleus in a CRM1 transporter-dependent manner and promotes binding of these transcription factors to the 14-3-3 chaperone proteins in the cytosol. PI3K/AKT signalling further antagonises FOXOdependent transcription by earmarking the phosphorylated proteins for proteasomal degradation (Plas \& Thompson 2003). Other kinases, such as serum- and glucocorticoidinducible kinase 1 (SGK1), casein kinase 1 (CK1) and dual-specificity tyrosine-phosphorylated and regulated $1 \mathrm{~A}$ (DYRK1A), have also been implicated in FOXO phosphorylation and nuclear export (Brunet et al. 2001, Woods et al. 2001, Rena et al. 2002, Feroze-Zaidi et al. 2007). In addition, stress signalling and activation of mitogenactivated protein kinase pathways, including JNK, ERK and p38, also converge on FOXO proteins, often enhancing their transcriptional activity (Essers et al. 2004, Asada et al. 2007, Yang et al. 2008, Clavel et al. 2010).

In addition to phosphorylation and ubiquitination, FOXO proteins are also subject to methylation, O-GlcNAcylation and acetylation. The sum of these posttranslational modifications determines the transcriptional output of FOXO proteins. A case in point is the functional consequences of altered FOXO1 acetylation. Protein acetylation is essentially controlled in a substrate-specific manner by a balance between histone acetyl transferase and histone deacetylase (HDAC) activity. In case of FOXO1, acetylation is mediated by p300/CBP, whereas deacetylation depends on binding to the class III HDAC SIRT1 (Matsuzaki et al. 2005, Calnan \& Brunet 2008). Intriguingly, SIRT1 promotes the pro-survival function of FOXO1, insofar that it directs FOXO activity away from pro-apoptotic genes (e.g. FASL and BIM) towards target genes involved in stress resistance (e.g. GADD45A) and cell cycle arrest (e.g. CDKN1B) genes (Vogt et al. 2005).

FOXO proteins are of particular relevance for cell fate decisions in hormone-responsive reproductive tissues, such as prostate, breast, ovary and uterus, because of their complex interactions with nuclear steroid receptors (Fig. 2). For example, FOXO1 binds PR, an interaction essential for endometrial homeostasis (Christian et al. 2002c, Takano et al. 2007), as outlined in more detail below. In breast cancer cells, FOXO3a engages in cross talk with the ER and inhibits its transcriptional activity of this nuclear receptor (Zou et al. 2008, Morelli et al. 2010). Accordingly, ectopic expression of FOXO3a in a breast cancer mouse model suppresses oestradiol-dependent tumourigenesis (Zou et al. 2008). In the normal prostate and early prostate cancers, the liganded AR induces the expression of genes involved in cell proliferation and survival (Li et al. 2008). FOXO proteins, including FOXO1 and FOXO3a, interact with the activated AR, thereby attenuating its DNA binding activity and inhibiting its ability to upregulate pro-apoptotic genes, such as FASL ( $\mathrm{Li}$ et al. 2003). In addition, interaction with FOXO proteins may further attenuate AR activity by preventing the recruitment of co-activators (Ma et al. 2009). Therefore, the loss of FOXO3a expression, or its inactivation by inhibitory phosphorylation and other posttranslational modifications, is a hallmark androgen-independent progression of human prostate cancer (Lynch et al. 2005, Cornforth et al. 2008, Yang \& Hung 2009).

\section{FOXO transcription factors in cycling endometrium}

As mentioned, FOXO1 is the most prominent and best characterised family member in human endometrium. It was first identified in this tissue as a transcriptional regulator of prolactin (PRL), a defining differentiation marker gene of decidualising endometrial stromal cells (Christian et al. 2002a,b). Subsequent siRNA depletion studies revealed that the transcription factor FOXO1 is also central to the 


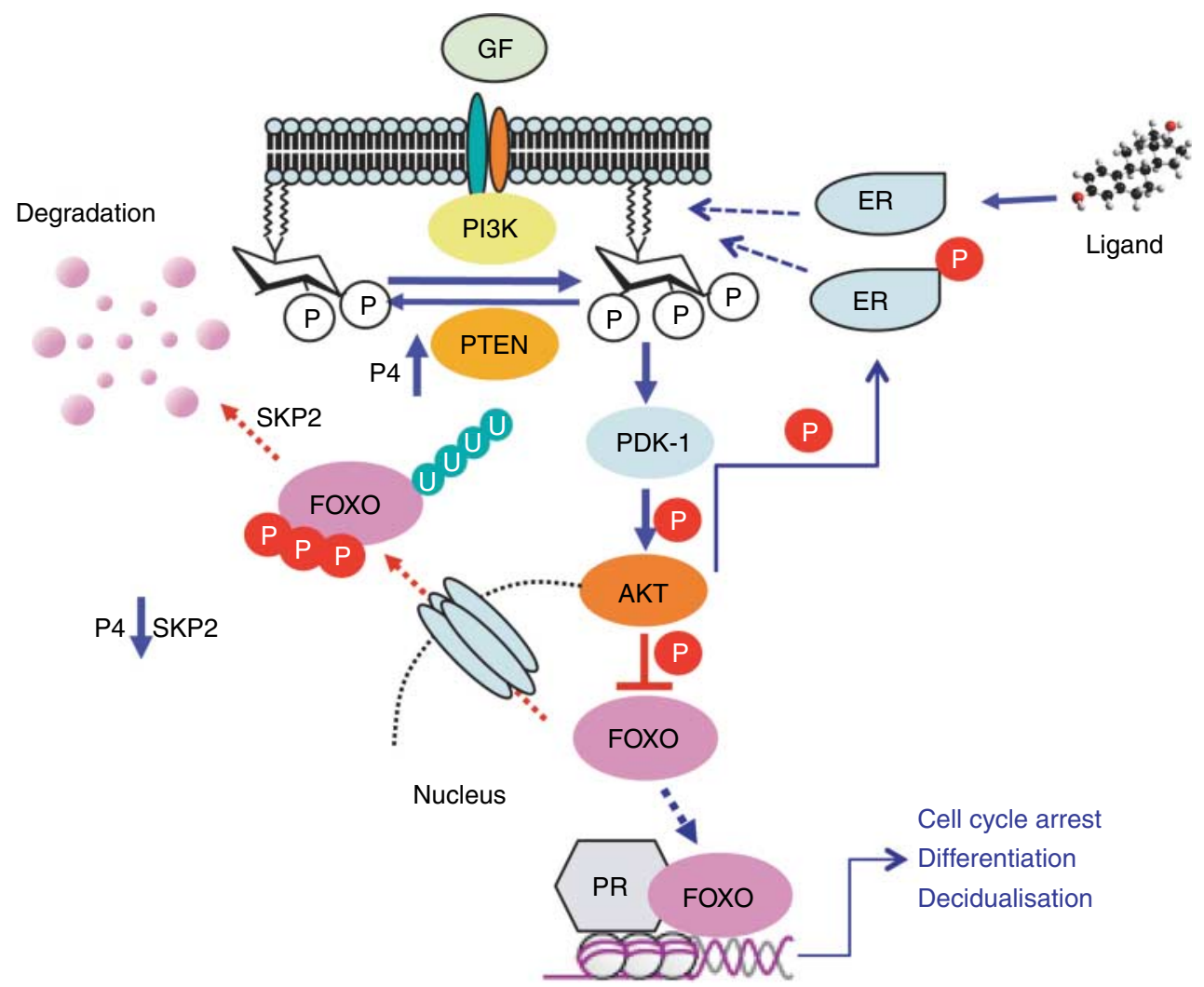

Figure 2 The effects of steroid hormone signalling on the PI3K/AKT/FOXO pathway. Progesterone signalling in normal endometrium promotes the transcriptional activity in FOXO1, which is necessary for decidualisation. Progesterone increases PTEN expression, which leads to PIP3 turnover and a consequent reduction in AKT signalling. Some FOXO1 remains unphosphorylated and nuclear, which enables FOXO1/PR target genes to be expressed. Progesterone also leads to activation of SGK1 and phosphorylation of FOXO1. Some FOXO1 is, therefore, translocated to the cytoplasm; however, progesterone also decreases the expression of SKP2, the FOXO1 ubiquitin ligase and inactive FOXO1 accumulates in the cytoplasm instead of being degraded. Loss of PTEN, which is observed in many cancers, promotes the accumulation of phosphatydlinositol-3,4,5-triphosphate (PIP3), which results in hyperactivity of AKT and FOXO phosphorylation. In the phosphorylated state, FOXO is excluded from the nucleus and degraded in the cytoplasm in a ubiquitin-dependent manner. FOXO target genes are, therefore, not expressed due to loss of FOXO. Oestradiol-bound ER can activate PI3K by binding to the p85 regulatory subunit and promote the generation of PIP3. AKT also phosphorylates ER, which further promotes the production of PIP3 and consequent AKT signalling.

induction of the decidual programme (Grinius et al. 2006). The expression of FOXO1 in mid-secretory endometrium coincides with that of several other transcriptional regulators of the decidual process, including p53, STAT5 and C/EBP $\beta$ (Christian et al. 2002a,b,c, Mak et al. 2002, Pohnke et al. 2004). Moreover, many of these factors are capable of physically interacting with the activated PR and regulate PRL expression by binding to a discrete region in the proximal decidual-specific promoter that contains overlapping FOXOand C/EBP $\beta$-DNA binding sites as well as PR response element half-sites. Furthermore, a recent study demonstrated that recruitment of FOXO1 to the decidual $P R L$ promoter converts HOXA11, a transcription factor essential for development and function of the female reproductive tract, from a repressor to a strong activator of gene expression (Lynch et al. 2009). These observations suggest that the activated PR serves as a platform for binding cAMP-induced transcription factors, including FOXO1, and that these multimeric complexes regulate the expression of decidual gene networks (Jones et al. 2006, Gellersen et al. 2007).

Although the primary signal for induction and nuclear accumulation of FOXO1 in decidualising endometrial cells is cAMP, its transcriptional output is tightly regulated by progesterone signalling through multiple mechanisms. First, progesterone triggers a reciprocal inhibition of AKT activity and enhanced SGK1 expression and phosphorylation, which in turn causes a partial translocation of FOXO1 to the cytoplasm (Feroze-Zaidi et al. 2007). Secondly, progesterone inhibits the expression of $\mathrm{Skp} 2$, the oncogenic subunit of the Skp1/Cul1/F-box protein complex that directs FOXO1 ubiquitination and proteasomal degradation (Huang et al. 2005). Consequently, decidual cells also accumulate a pool of inactive FOXO1 in the cytoplasm, in addition to nuclear FOXO1, in response to continuous progesterone signalling. Withdrawal of progesterone from differentiated cultures leads to re-accumulation of nuclear FOXO1, enhances BIM 
expression and induces cell death, a response that may initiate menstrual shedding of the endometrium upon falling circulating progesterone levels at the end of the cycle (Labied et al. 2006).

By combining small interfering RNA technology and microarray screening, Takano et al. (2007) found that $\sim 15 \%$ of all regulated upon differentiation of human endometrial fibroblasts into decidual cells are under direct or indirect control of FOXO1. Not surprisingly, several FOXO1dependent genes encode for major differentiation markers (e.g. IGFBP1, PRL and LEFTY2) as well as for numerous proteins involved in cell cycle regulation. For example, FOXO1 regulates the induction of CDKN1C $\left(\mathrm{p} 57^{\mathrm{Kip} 2}\right)$, a cyclin-dependent inhibitor involved in G1 arrest, while simultaneously repressing several genes important for DNA replication/S phase (e.g. MCM5), G2/M transition (e.g. CCNB1, CCNB2, CDC2, BIRC5 and BRIP1) or mitosis (e.g. PRC1, NUSAP1, CENPF, SPBC25 and ASPM). Decidualisation of endometrial stromal cells is further associated with silencing of the JNK signalling pathway and its downstream target FOXO3a, which in turn protects these cells against oxidative cell death in pregnancy (Kajihara et al. 2006, Leitao et al. 2010).

The ability of FOXO proteins to regulate cellular homeostasis, i.e. to activate or repress the appropriate gene networks in response to hormonal, growth factor and environmental cues reflects the fact that a wide range of signal transduction pathways converge on these transcription factors and, conversely, that FOXO protein can regulate the activity of upstream pathways. For example, FOXO transcription factors bind to SMAD3 and SMAD4 in response to transforming growth factor- $\beta$ (TGF- $\beta$ ) signalling and to $\beta$-catenin upon activation of the canonical WNT pathway (Seoane et al. 2004, Essers et al. 2005). On the other hand, FOXO1 induces the expression of INSR in endometrial cells, encoding the insulin receptor as well as WNT4 and BMP and activin membrane-bound inhibitor (BAMBI; Takano et al. 2007). BAMBI is a transmembrane glycoprotein related to TGF- $\beta$ family type I receptors. However, it lacks an intracellular kinase domain and serves as a potent inhibitor of BMP, activin and TGF- $\beta$ signalling (Sekiya et al. 2004). This ability of FOXO proteins to engage in complex feedback mechanisms that fine-tune the activity of upstream regulatory pathways is not confined to endometrial cells. For example, in chemoresistant cancer cells, FOXO3a has been shown to induce PIK3CA expression, a gene that encodes for the Class 1A PI3K catalytic subunit $\mathrm{p} 110 \alpha$. Importantly, $\mathrm{p} 110 \alpha$ is a rate-limiting factor of PI3K/AKT activation in response to growth factor signalling (Hui et al. 2008). In Drosophila, the $\mathrm{dFOXO}$ orthologue also induces the expression of the insulin receptor (Puig et al. 2003), resulting in increased PI3K activity and cell growth under low-nutrient conditions. Another example involves hepatocytes where FOXO1 represses the expression of tribble 3 ( $\operatorname{Trb} 3$ ), a pseudokinase that antagonises AKT (Matsumoto et al. 2006). Thus, depending on the cellular and environmental context, FOXO proteins seem to be capable of enhancing as well as inhibiting the activity of the upstream inhibitory PI3K/AKT pathway.

FOXO1 is also expressed in the epithelial compartment of the endometrium, but little is known of its function in these cells during the menstrual cycle. Based on the cell line work, however, there is evidence that expression of FOXO1 in epithelial endometrial cells is under direct control of that activated PR and essential to mediate the antiproliferative effects of progesterone and synthetic progestins (Shimizu et al. 2010).

\section{The miRNA-FOXO axis in endometrial carcinogenesis}

Endometrial cancer is the commonest malignancy of the female genital tract in Europe and North America with an incidence of $\sim 22$ per 100000 women per year) (Bray et al. 2005, Parkin et al. 2005). Worldwide, $\sim 50000$ patients die from this cancer each year. Endometrial carcinoma can be divided into two groups: type I (endometrioid) and type II (non-endometrioid). Type I, which accounts for $80 \%$ of all endometrial carcinomas, is oestrogen related, low grade, affects pre- and peri-menopausal women and is often preceded by complex atypical endometrial hyperplasia. In contrast, type II tumours are not oestrogen driven and mostly develop in atrophic endometrium.

The PTEN tumour suppressor gene encodes a protein/ lipid phosphatase that dephosphorylates phosphatidylinositol 3,4,5-triphosphate, the second messenger of the PI3K signalling pathway. Thus, PTEN antagonises PI3K activity, inhibits AKT and thus enhances FOXO activity (Fig. 2). It has been estimated that PTEN is either completely lost or mutated in $37-51 \%$ of primary endometrioid endometrial cancers (EEC), the highest incidence of mutation in this tumour suppressor gene in any cancer analysed to date (Kong et al. 1997). PTEN is already mutated in $20 \%$ of endometrial hyperplasia (Maxwell et al. 1998a,b, Risinger et al. 1998), indicating that is a very early genetic event in the multi-step process leading to EEC. Furthermore, SKP2, the FOXO1 ubiquitin ligase, is overexpressed in endometrial cancer (Kau et al. 2003, Lahav-Baratz et al. 2004). Thus, based on the loss of PTEN, leading to PI3K/AKT hyperactivity, and increased SKP2 expression, it was predicted that FOXO proteins would be rapidly degraded in EEC. Analysis of 60 surgical specimens revealed indeed that FOXO1 immunoreactivity was undetectable in $~ 75-80 \%$ of EEC, irrespective of the grade of the tumours (Goto et al. 2008). However, additional analysis demonstrated that loss of FOXO1 expression in EEC was not primarily a consequence of increased protein turnover. Unexpectedly, FOXO1 transcripts were sixfold less abundant in EEC than in cycling endometrium, whereas the expression of FOXO3a and FOXO4 mRNAs did not differ.

Methylation-specific PCR analysis revealed that the FOXO1 promoter becomes methylated in EEC, but only partially and inconsistently (Goto et al. 2008). At the same 
Table 1 Differentially expressed miRNAs in endometrioid endometrial cancers (EEC)

Study (reference)

Cohn et al. (2010)

Ratner et al. (2010)

Chung et al. (2009)

Wu et al. (2009)

Boren et al. (2008)
miRNAs differentially expressed in endometrioid endometrial cancers (EEC)

Stage I/IA grade I EEC versus benign tissue from control patients

$\uparrow:$ miR-9, miR-19b, miR-146, miR-181c, miR-183, miR-200c, miR-205, miR-223, miR-423, miR-425

$\downarrow$ : let-7a, miR-32, miR-33b, miR-369, miR-409, miR-424, miR-431, miR-451, miR-496, miR-503 miR-516

EEC carcinoma versus benign tissue from control patients

$\uparrow:$ miR-34a, miR-182, miR-183, miR-200a, miR-205, miR-572, miR-622, miR-650

$\downarrow:$ miR-411, miR-487b

EEC versus benign tissue from control patients

$\uparrow$ : miR-10a, miR-23a, miR-25, miR-28, miR-34a, miR-95, miR-103, miR-106a, miR-107, miR-130b, miR-141, miR-151, miR-155, miR-17-5p, miR-182, miR-183, miR-184, miR-191, miR-194, miR-200a, miR-200c, miR-203, miR-205, miR-210 miR-215 miR-223 miR-301 miR-325 miR-326 miR-330

$\downarrow:$ miR-125b, miR-296, miR-323

EEC adenocarcinoma versus adjacent benign tissue from EEC patients

$\uparrow$ : miR-10a, miR-31, miR-96, miR-133b, miR-141, miR-142-5p, miR-155, miR-182, miR-200a, miR-200b, miR-200c, miR-203, miR-205, miR-210, miR-363, miR-429, miR-432, miR-449

$\downarrow$ : miR-99b, miR-133, miR-193a, miR-193b, miR-204, miR-368

EEC versus atypical hyperplasia versus normal endometrium

$\uparrow$ : let-7c, miR-103, miR-106a, miR-107, miR-181a, miR-185, miR-210, miR-423

$\downarrow$ : let-7i, miR-30c, miR-152, miR-193, miR-221 time, it became increasingly apparent that deregulated miRNA expression was a hallmark of endometrial carcinogenesis (Table 1). Initial profiling analysis of miRNAs in normal endometrium, atypical hyperplasia and endometrial cancer uncovered 13 miRNA species to be differentially expressed. Within this group, five miRNAs (miR-let 7i, miR-30c, miR-221, miR-193 and miR-152) were decreased and eight (miR-let 7c, miR-185, miR-106a, miR-181a, miR-210, miR-423, miR-103 and miR-107) increased upon transition from normal endometrium to atypical hyperplasia to cancer (Boren et al. 2008). Among the most differentially expressed miRNAs, miR-205, miR-182 and miR-200a are most upregulated in endometrioid samples, whereas mir-411 was most downregulated in cancer samples compared with benign tissue (Ratner et al. 2010). Another small-scale screening analysis revealed $30 \mathrm{miRNAs}$ that were significantly dysregulated in EEC (Chung et al. 2009). Together, these miRNA profiling studies demonstrated that miRNA expression is commonly dysregulated in human endometrial cancer and that there are putative miRNA signatures for endometrial cancer (Takano et al. 2007, Boren et al. 2008, Chung et al. 2009, Wu et al. 2009, Cohn et al. 2010, Ratner et al. 2010). For example, the miRNAs miR-182, miR-183 and $\mathrm{miR}-205$ are consistently upregulated in endometrial cancer samples compared with benign tissues. However, despite the strong correlations between miRNA expression patterns and endometrial cancer, little is known about the role of these differentially expressed miRNAs and their targets in endometrial cancer tumourigenesis and progression (Table 2; Huang et al. 2009, Myatt et al. 2010).

A recent expression profiling study of miRNAs in normal endometrium and EEC has identified an inverse correlation between FOXO1 expression and the abundance of several of the in silico-predicted miRNAs (i.e. miR-9, miR-27, miR-96, miR-153, miR-182, miR-183 and miR-186) that potentially bind the $3^{\prime}-\mathrm{UTR}$ of FOXO1 transcripts (Myatt et al. 2010). This finding suggests that loss of FOXO1 expression in endometrial cancer may be mediated by miRNAs. Consistently, these differentially expressed miRNAs are also overexpressed in the endometrial cancer cell line Ishikawa, which expresses low levels of FOXO1 but not in HEC-1B cells, another endometrial cancer cell line characterised by high FOXO1 expression. Importantly, overexpression of any of the differentially expressed miRNAs in HEC-1B cells was sufficient to significantly reduce FOXO1. Conversely, FOXO1 expression could be efficiently restored in the Ishikawa cell line upon simultaneous depletion of miR-9, miR-27, miR-96, miR-153, miR-183 and miR-186. Induction of FOXO1 in Ishikawa cells by miR inhibitors was accompanied by G1 cell cycle arrest and cell death and was attenuated by the small interfering RNA-mediated downregulation of FOXO1 expression. These findings suggest that a group of miRNAs act coordinately to repress FOXO1 expression, which in turn deregulates cell cycle control and apoptotic responses in endometrial cancer. A similar scenario may contribute to breast cancer development

Table 2 Validated functional consequences for miRNA in endometrioid endometrial cancers

\section{Functional miRNA studies in endometrial cancer}

\begin{tabular}{|c|c|}
\hline Study (reference) & Main functional findings for miRNA \\
\hline Cohn et al. (2010) & $\begin{array}{l}\text { Repression of miR-129-2 expression by } \\
\text { epigenetic mechanisms leads to SOX4 } \\
\text { overexpression in endometrial cancer }\end{array}$ \\
\hline Myatt et al. (2010) & $\begin{array}{l}\text { miR-9, miR-27, miR-96, miR-153, miR-182, } \\
\text { miR-183 and miR-186 regulate FOXO1 } \\
\text { expression in endometrial cancer cell lines }\end{array}$ \\
\hline
\end{tabular}


where FOXO1 transcripts and expression are also downregulated in tumour samples compared with normal tissue. Silencing of the miRNA processing enzymes, DROSHA and DICER, in breast cancer cell lines results in enhanced FOXO1 expression (Guttilla \& White 2009). Indeed, three miRNAs (miR-27a, miR-96 and miR-182) that limit FOXO1 expression in EEC are also highly expressed in breast cancer cells with low FOXO1 levels. Antisense inhibitors to each of these miRNAs significantly increase endogenous FOXO1 expression and decrease cell proliferation and viability (Guttilla \& White 2009). Thus, in terms of disabling the tumor suppressor function of FOXO1 in hormone-responsive endometrial and breast cancer, miRNAs play an important, if not central, role.

\section{Future directions: miRNAs as cancer biomarkers and therapeutic targets}

MiRNA represents a new class of biomarkers that can complement existing conventional markers, including metabolites, antigens and mRNA transcripts. The fact that miRNAs remain largely intact in formalin-fixed, paraffinembedded clinical samples highlights their potential in molecular phenotyping of benign and malignant reproductive disorders as well as for monitoring treatment efficacy (Bitossi et al. 2008, Szafranska et al. 2008, Tam 2008, Jorgensen et al. 2010, Nuovo 2010, Schuster et al. 2010). Furthermore, recent evidence suggests that some neoplastic processes, for example, ovarian cancer, generate mRNA profiles in blood cells characteristic of the tumours, suggesting that whole blood miRNA profiling could be used for diagnostic purposes (Balch et al. 2009, Lodes et al. 2009, Resnick et al. 2009, Hausler et al. 2010). Evidence for miRNA secretion by the trophoblast has already been established, but it is not yet known if secretion is also a feature of decidualising endometrium. Nevertheless, the clear potential exists to use circulating miRNAs for the prediction of pregnancy complications associated with impaired placentation, such as miscarriage, pre-eclampsia and foetal growth restriction.

In the context of proliferative disorders of the endometrium, such as endometriosis and EEC, it is striking, but perhaps not entirely surprising, that many deregulated miRNAs potentially target cell cycle regulators, oncogenes and intermediates in the PI3K/AKT/FOXO as well as the steroid hormone signalling pathways. This observation emphasises the importance of hormone-dependent coordinated miRNA expression in ensuring tissue homeostasis during the process of cyclic cell proliferation, differentiation, apoptosis and tissue breakdown. Besides targeting oncomiRs in the context of endometrial hyperplasia or cancer, it is conceivable that miRNAs or components of the processing machinery could also be targeted for fertility control. Therapeutic interventions, however, will require a much more in-depth understanding of the role of miRNA in modulating the endometrial responses to ovarian hormones.
Thus, miRNAs represent an important class of diagnostic and prognostic biomarkers and therapeutic targets that warrant further investigation before their true potential can be realised.

\section{Declaration of interest}

The authors declare that there is no conflict of interest that could be perceived as prejudicing the impartiality of the research reported.

\section{Funding}

This work was partly supported by Cancer Research UK (grant number C37/A12011).

\section{References}

Adam AP, George A, Schewe D, Bragado P, Iglesias BV, Ranganathan AC, Kourtidis A, Conklin DS \& Aguirre-Ghiso JA 2009 Computational identification of a p38SAPK-regulated transcription factor network required for tumor cell quiescence. Cancer Research 69 5664-5672. (doi:10.1158/0008-5472.CAN-08-3820)

Ahn HW, Morin RD, Zhao H, Harris RA, Coarfa C, Chen ZJ, Milosavljevic A, Marra MA \& Rajkovic A 2010 MicroRNA transcriptome in the newborn mouse ovaries determined by massive parallel sequencing. Molecular Human Reproduction 16 463-471. (doi:10.1093/molehr/gaq017)

Arden KC 2008 FOXO animal models reveal a variety of diverse roles for FOXO transcription factors. Oncogene 27 2345-2350. (doi:10.1038/onc. 2008.27)

Asada S, Daitoku H, Matsuzaki H, Saito T, Sudo T, Mukai H, Iwashita S, Kako K, Kishi T, Kasuya Y et al. 2007 Mitogen-activated protein kinases, Erk and p38, phosphorylate and regulate Foxo1. Cellular Signalling 19 519-527. (doi:10.1016/j.cellsig.2006.08.015)

Balch C, Fang F, Matei DE, Huang TH \& Nephew KP 2009 Minireview: epigenetic changes in ovarian cancer. Endocrinology 150 4003-4011. (doi:10.1210/en.2009-0404)

Bitossi R, Sculli CM, Tampellini M, Alabiso I, Brizzi MP, Ferrero A, Ottone A, Bellini E, Gorzegno G, Berruti A et al. 2008 Gemcitabine and protracted 5-fluorouracil infusion as third-line chemotherapy in refractory colorectal cancer patients. Anticancer Research 28 3055-3060.

Boren T, Xiong Y, Hakam A, Wenham R, Apte S, Wei Z, Kamath S, Chen DT, Dressman H \& Lancaster JM 2008 MicroRNAs and their target messenger RNAs associated with endometrial carcinogenesis. Gynecologic Oncology 110 206-215. (doi:10.1016/j.ygyno.2008.03.023)

Bouchard C, Lee S, Paulus-Hock V, Loddenkemper C, Eilers M \& Schmitt CA 2007 FoxO transcription factors suppress Myc-driven lymphomagenesis via direct activation of Arf. Genes and Development 21 2775-2787. (doi:10.1101/gad.453107)

Bray F, Loos AH, McCarron P, Weiderpass E, Arbyn M, Moller H, Hakama M \& Parkin DM 2005 Trends in cervical squamous cell carcinoma incidence in 13 European countries: changing risk and the effects of screening. Cancer Epidemiology, Biomarkers and Prevention 14 677-686. (doi:10.1158/ 1055-9965.EPI-04-0569)

Brosens JJ \& Gellersen B 2006 Death or survival - progesterone-dependent cell fate decisions in the human endometrial stroma. Journal of Molecular Endocrinology 36 389-398. (doi:10.1677/jme.1.02060)

Brosens JJ, Pijnenborg R \& Brosens IA 2002 The myometrial junctional zone spiral arteries in normal and abnormal pregnancies: a review of the literature. American Journal of Obstetrics and Gynecology 187 1416-1423. (doi:10.1067/mob.2002.127305) 
Brunet A, Park J, Tran H, Hu LS, Hemmings BA \& Greenberg ME 2001 Protein kinase SGK mediates survival signals by phosphorylating the forkhead transcription factor FKHRL1 (FOXO3a). Molecular and Cellular Biology 21 952-965. (doi:10.1128/MCB.21.3.952-965.2001)

Burgering BM 2008 A brief introduction to FOXOlogy. Oncogene 27 2258-2262. (doi:10.1038/onc.2008.29)

Burney RO, Talbi S, Hamilton AE, Vo KC, Nyegaard M, Nezhat CR, Lessey BA \& Giudice LC 2007 Gene expression analysis of endometrium reveals progesterone resistance and candidate susceptibility genes in women with endometriosis. Endocrinology 148 3814-3826. (doi:10.1210/ en.2006-1692)

Burney RO, Hamilton AE, Aghajanova L, Vo KC, Nezhat CN, Lessey BA \& Giudice LC 2009 MicroRNA expression profiling of eutopic secretory endometrium in women with versus without endometriosis. Molecular Human Reproduction 15 625-631. (doi:10.1093/molehr/gap068)

Cai X, Hagedorn CH \& Cullen BR 2004 Human microRNAs are processed from capped, polyadenylated transcripts that can also function as mRNAs. RNA 10 1957-1966. (doi:10.1261/rna.7135204)

Calnan DR \& Brunet A 2008 The FoxO code. Oncogene 27 2276-2288. (doi:10.1038/onc.2008.21)

Castellano L, Giamas G, Jacob J, Coombes RC, Lucchesi W, Thiruchelvam P, Barton G, Jiao LR, Wait R, Waxman J et al. 2009 The estrogen receptoralpha-induced microRNA signature regulates itself and its transcriptional response. PNAS 106 15732-15737. (doi:10.1073/pnas.0906947106)

Chakrabarty A, Tranguch S, Daikoku T, Jensen K, Furneaux H \& Dey SK 2007 MicroRNA regulation of cyclooxygenase-2 during embryo implantation. PNAS 104 15144-15149. (doi:10.1073/pnas.0705917104)

Chekulaeva M \& Filipowicz W 2009 Mechanisms of miRNA-mediated posttranscriptional regulation in animal cells. Current Opinion in Cell Biology 21 452-460. (doi:10.1016/j.ceb.2009.04.009)

Choi WY, Giraldez AJ \& Schier AF 2007 Target protectors reveal dampening and balancing of Nodal agonist and antagonist by miR-430. Science 318 271-274. (doi:10.1126/science.1147535)

Christian M, Mak I, White JO \& Brosens JJ 2002a Mechanisms of decidualization. Reproductive BioMedicine Online 4 (Supplement 3) 24-30.

Christian M, Pohnke Y, Kempf R, Gellersen B \& Brosens JJ $2002 b$ Functional association of $\mathrm{PR}$ and CCAAT/enhancer-binding protein beta isoforms: promoter-dependent cooperation between PR-B and liver-enriched inhibitory protein, or liver-enriched activatory protein and PR-A in human endometrial stromal cells. Molecular Endocrinology 16 141-154. (doi:10.1210/me.16.1.141)

Christian M, Zhang X, Schneider-Merck T, Unterman TG, Gellersen B, White JO \& Brosens JJ 2002c Cyclic AMP-induced forkhead transcription factor, FKHR, cooperates with CCAAT/enhancer-binding protein beta in differentiating human endometrial stromal cells. Journal of Biological Chemistry 277 20825-20832. (doi:10.1074/jbc.M201018200)

Chung TK, Cheung TH, Huen NY, Wong KW, Lo KW, Yim SF, Siu NS, Wong YM, Tsang PT, Pang MW et al. 2009 Dysregulated microRNAs and their predicted targets associated with endometrioid endometrial adenocarcinoma in Hong Kong women. International Journal of Cancer 124 1358-1365. (doi:10.1002/ijc.24071)

Clavel S, Siffroi-Fernandez S, Coldefy AS, Boulukos K, Pisani DF \& Derijard B 2010 Regulation of the intracellular localization of Foxo3a by stress-activated protein kinase signaling pathways in skeletal muscle cells. Molecular and Cellular Biology 30 470-480. (doi:10.1128/MCB.00666-09)

Cloke B, Shah K, Kaneda H, Lavery S, Trew G, Fusi L, Higham J, Dina RE, Ghaem-Maghami S, Ellis $\mathrm{P}$ et al. 2010 The poly(c)-binding protein-1 regulates expression of the androgen receptor. Endocrinology 151 3954-3964. (doi:10.1210//en.2009-1264)

Cohn DE, Fabbri M, Valeri N, Alder H, Ivanov I, Liu CG, Croce CM \& Resnick KE 2010 Comprehensive miRNA profiling of surgically staged endometrial cancer. American Journal of Obstetrics and Gynecology 202 656.e1-656.e8. (doi:10.1016/j.ajog.2010.02.051)

Cornforth AN, Davis JS, Khanifar E, Nastiuk KL \& Krolewski JJ 2008 FOXO3a mediates the androgen-dependent regulation of FLIP and contributes to TRAIL-induced apoptosis of LNCaP cells. Oncogene $\mathbf{2 7}$ 4422-4433. (doi:10.1038/onc.2008.80)
Di Leva G, Gasparini P, Piovan C, Ngankeu A, Garofalo M, Taccioli C, Iorio MV, Li M, Volinia S, Alder H et al. 2010 MicroRNA cluster 221-222 and estrogen receptor alpha interactions in breast cancer. Journal of the National Cancer Institute 102 706-721. (doi:10.1093/jnci/djq102)

Du T \& Zamore PD 2005 microPrimer: the biogenesis and function of microRNA. Development 132 4645-4652. (doi:10.1242/dev.02070)

Du T \& Zamore PD 2007 Beginning to understand microRNA function. Cell Research 17 661-663. (doi:10.1038/cr.2007.67)

Eskenazi B \& Warner ML 1997 Epidemiology of endometriosis. Obstetrics and Gynecology Clinics of North America 24 235-258. (doi:10.1016/S08898545(05)70302-8)

Essers MA, Weijzen S, de Vries-Smits AM, Saarloos I, de Ruiter ND, Bos JL \& Burgering BM 2004 FOXO transcription factor activation by oxidative stress mediated by the small GTPase Ral and JNK. EMBO Journal $\mathbf{2 3}$ 4802-4812. (doi:10.1038/sj.emboj.7600476)

Essers MA, de Vries-Smits LM, Barker N, Polderman PE, Burgering BM \& Korswagen HC 2005 Functional interaction between beta-catenin and FOXO in oxidative stress signaling. Science 308 1181-1184. (doi:10.1126/ science.1109083)

Feroze-Zaidi F, Fusi L, Takano M, Higham J, Salker MS, Goto T, Edassery S, Klingel K, Boini KM, Palmada M et al. 2007 Role and regulation of the serum- and glucocorticoid-regulated kinase 1 in fertile and infertile human endometrium. Endocrinology 148 5020-5029. (doi:10.1210/en. 2007-0659)

Fiedler SD, Carletti MZ, Hong X \& Christenson LK 2008 Hormonal regulation of MicroRNA expression in periovulatory mouse mural granulosa cells. Biology of Reproduction 79 1030-1037. (doi:10.1095/ biolreprod.108.069690)

Filigheddu N, Gregnanin I, Porporato PE, Surico D, Perego B, Galli L, Patrignani C, Graziani A \& Surico N 2010 Differential expression of microRNAs between eutopic and ectopic endometrium in ovarian endometriosis. Journal of Biomedicine and Biotechnology 2010 369549. (doi:10. $1155 / 2010 / 369549)$

Filipowicz W, Bhattacharyya SN \& Sonenberg N 2008 Mechanisms of posttranscriptional regulation by microRNAs: are the answers in sight? Nature Reviews. Genetics 9 102-114. (doi:10.1038/nrg2290)

Friedman RC, Farh KK, Burge CB \& Bartel DP 2009 Most mammalian mRNAs are conserved targets of microRNAs. Genome Research 19 92-105. (doi:10.1101/gr.082701.108)

Fu Z \& Tindall DJ 2008 FOXOs, cancer and regulation of apoptosis. Oncogene 27 2312-2319. (doi:10.1038/onc.2008.24)

Gellersen B, Brosens IA \& Brosens JJ 2007 Decidualization of the human endometrium: mechanisms, functions, and clinical perspectives. Seminars in Reproductive Medicine 25 445-453. (doi:10.1055/s-2007-991042)

Gomes AR, Brosens JJ \& Lam EW 2008 Resist or die: FOXO transcription factors determine the cellular response to chemotherapy. Cell Cycle 7 3133-3136. (doi:10.4161/cc.7.20.6920)

Goto T, Takano M, Albergaria A, Briese J, Pomeranz KM, Cloke B, Fusi L, Feroze-Zaidi F, Maywald N, Sajin M et al. 2008 Mechanism and functional consequences of loss of FOXO1 expression in endometrioid endometrial cancer cells. Oncogene 27 9-19. (doi:10.1038/sj.onc.1210626)

Griffiths-Jones S 2010 miRBase: microRNA sequences and annotation. Current Protocols in Bioinformatics Chapter 12 Unit 12.9 1-10. (doi:10.1002/ 0471250953.bi1209s29)

Grinius L, Kessler C, Schroeder J \& Handwerger S 2006 Forkhead transcription factor FOXO1A is critical for induction of human decidualization. Journal of Endocrinology 189 179-187. (doi:10.1677/joe. 1.06451)

Guo H, Ingolia NT, Weissman JS \& Bartel DP 2010 Mammalian microRNAs predominantly act to decrease target mRNA levels. Nature 466 835-840. (doi:10.1038/nature09267)

Guttilla IK \& White BA 2009 Coordinate regulation of FOXO1 by miR-27a, miR-96, and miR-182 in breast cancer cells. Journal of Biological Chemistry 284 23204-23216. (doi:10.1074/jbc.M109.031427)

Han J, Lee Y, Yeom KH, Kim YK, Jin H \& Kim VN 2004 The DroshaDGCR 8 complex in primary microRNA processing. Genes and Development 18 3016-3027. (doi:10.1101/gad.1262504) 
Hausler SF, Keller A, Chandran PA, Ziegler K, Zipp K, Heuer S, Krockenberger M, Engel JB, Honig A, Scheffler M et al. 2010 Whole blood-derived miRNA profiles as potential new tools for ovarian cancer screening. British Journal of Cancer 103 693-700. (doi:10.1038/sj.bjc. 6605833)

Ho KK, Myatt SS \& Lam EW 2008 Many forks in the path: cycling with FoxO. Oncogene 27 2300-2311. (doi:10.1038/onc.2008.23)

Hu SJ, Ren G, Liu JL, Zhao ZA, Yu YS, Su RW, Ma XH, Ni H, Lei W \& Yang ZM 2008 MicroRNA expression and regulation in mouse uterus during embryo implantation. Journal of Biological Chemistry 283 23473-23484. (doi:10.1074/jbc.M800406200)

Huang H \& Tindall DJ 2007 Dynamic FoxO transcription factors. Journal of Cell Science 120 2479-2487. (doi:10.1242/jcs.001222)

Huang H, Regan KM, Wang F, Wang D, Smith DI, van Deursen JM \& Tindall DJ 2005 Skp2 inhibits FOXO1 in tumor suppression through ubiquitin-mediated degradation. PNAS 102 1649-1654. (doi:10.1073/ pnas.0406789102)

Huang YW, Liu JC, Deatherage DE, Luo J, Mutch DG, Goodfellow PJ, Miller DS \& Huang TH 2009 Epigenetic repression of microRNA-129-2 leads to overexpression of SOX4 oncogene in endometrial cancer. Cancer Research 69 9038-9046. (doi:10.1158/0008-5472.CAN-09-1499)

Hui RC, Gomes AR, Constantinidou D, Costa JR, Karadedou CT, Fernandez de Mattos S, Wymann MP, Brosens JJ, Schulze A \& Lam EW 2008 The forkhead transcription factor FOXO3a increases phosphoinositide-3 kinase/Akt activity in drug-resistant leukemic cells through induction of PIK3CA expression. Molecular and Cellular Biology 28 5886-5898. (doi:10.1128/MCB.01265-07)

Jacobs FM, van der Heide LP, Wijchers PJ, Burbach JP, Hoekman MF \& Smidt MP 2003 FoxO6, a novel member of the FoxO class of transcription factors with distinct shuttling dynamics. Journal of Biological Chemistry 278 35959-35967. (doi:10.1074/jbc.M302804200)

Jones MC, Fusi L, Higham JH, Abdel-Hafiz H, Horwitz KB, Lam EW \& Brosens JJ 2006 Regulation of the SUMO pathway sensitizes differentiating human endometrial stromal cells to progesterone. PNAS 103 16272-16277. (doi:10.1073/pnas.0603002103)

Jorgensen S, Baker A, Moller S \& Nielsen BS 2010 Robust one-day in situ hybridization protocol for detection of microRNAs in paraffin samples using LNA probes. Methods 52 375-381. (doi:10.1016/j.ymeth. 2010.07.002)

Kajihara T, Jones M, Fusi L, Takano M, Feroze-Zaidi F, Pirianov G, Mehmet H, Ishihara O, Higham JM, Lam EW et al. 2006 Differential expression of FOXO1 and FOXO3a confers resistance to oxidative cell death upon endometrial decidualization. Molecular Endocrinology 20 2444-2455. (doi:10.1210/me.2006-0118)

Kao LC, Germeyer A, Tulac S, Lobo S, Yang JP, Taylor RN, Osteen K, Lessey BA \& Giudice LC 2003 Expression profiling of endometrium from women with endometriosis reveals candidate genes for disease-based implantation failure and infertility. Endocrinology 144 2870-2881. (doi:10.1210/en.2003-0043)

Kau TR, Schroeder F, Ramaswamy S, Wojciechowski CL, Zhao JJ, Roberts TM, Clardy J, Sellers WR \& Silver PA 2003 A chemical genetic screen identifies inhibitors of regulated nuclear export of a Forkhead transcription factor in PTEN-deficient tumor cells. Cancer Cell 4 463-476. (doi:10.1016/S1535-6108(03)00303-9)

Kong D, Suzuki A, Zou TT, Sakurada A, Kemp LW, Wakatsuki S, Yokoyama T, Yamakawa H, Furukawa T, Sato M et al. 1997 PTEN1 is frequently mutated in primary endometrial carcinomas. Nature Genetics 17 143-144. (doi:10.1038/ng1097-143)

Kuokkanen S, Chen B, Ojalvo L, Benard L, Santoro N \& Pollard JW 2010 Genomic profiling of microRNAs and messenger RNAs reveals hormonal regulation in microRNA expression in human endometrium. Biology of Reproduction 82 791-801. (doi:10.1095/biolreprod.109.081059)

Labied S, Kajihara T, Madureira PA, Fusi L, Jones MC, Higham JM, Varshochi R, Francis JM, Zoumpoulidou G, Essafi A et al. 2006 Progestins regulate the expression and activity of the forkhead transcription factor FOXO1 in differentiating human endometrium. Molecular Endocrinology 20 35-44. (doi:10.1210/me.2005-0275)
Lahav-Baratz S, Ben-Izhak O, Sabo E, Ben-Eliezer S, Lavie O, Ishai D, Ciechanover A \& Dirnfeld M 2004 Decreased level of the cell cycle regulator p27 and increased level of its ubiquitin ligase Skp2 in endometrial carcinoma but not in normal secretory or in hyperstimulated endometrium. Molecular Human Reproduction 10 567-572. (doi:10.1093/molehr/gah084)

Lam EW, Francis RE \& Petkovic M 2006 FOXO transcription factors: key regulators of cell fate. Biochemical Society Transactions 34 722-726. (doi:10. 1042/BST0340722)

Leitao B, Jones MC, Fusi L, Higham J, Lee Y, Takano M, Goto T, Christian M, Lam EW \& Brosens JJ 2010 Silencing of the JNK pathway maintains progesterone receptor activity in decidualizing human endometrial stromal cells exposed to oxidative stress signals. FASEB Journal 24 1541-1551. (doi:10.1096/fj.09-149153)

Li P, Lee H, Guo S, Unterman TG, Jenster G \& Bai W 2003 AKT-independent protection of prostate cancer cells from apoptosis mediated through complex formation between the androgen receptor and FKHR. Molecular and Cellular Biology 23 104-118. (doi:10.1128/MCB.23. 1.104-118.2003)

Li Y, Wang Z, Kong D, Li R, Sarkar SH \& Sarkar FH 2008 Regulation of Akt/FOXO3a/GSK-3beta/AR signaling network by isoflavone in prostate cancer cells. Journal of Biological Chemistry 283 27707-27716. (doi:10.1074/ jbc.M802759200)

Lin SL, Chang D \& Ying SY 2005 Asymmetry of intronic pre-miRNA structures in functional RISC assembly. Gene 356 32-38. (doi:10.1016/ j.gene.2005.04.036)

Liu WH, Yeh SH, Lu CC, Yu SL, Chen HY, Lin CY, Chen DS \& Chen PJ 2009 MicroRNA-18a prevents estrogen receptor-alpha expression, promoting proliferation of hepatocellular carcinoma cells. Gastroenterology 136 683-693. (doi:10.1053/j.gastro.2008.10.029)

Lodes MJ, Caraballo M, Suciu D, Munro S, Kumar A \& Anderson B 2009 Detection of cancer with serum miRNAs on an oligonucleotide microarray. PLoS ONE 4 e6229. (doi:10.1371/journal.pone.0006229)

Luo SS, Ishibashi O, Ishikawa G, Ishikawa T, Katayama A, Mishima T, Takizawa T, Shigihara T, Goto T, Izumi A et al. 2009 Human villous trophoblasts express and secrete placenta-specific microRNAs into maternal circulation via exosomes. Biology of Reproduction 81 717-729. (doi:10.1095/biolreprod.108.075481)

Lynch RL, Konicek BW, McNulty AM, Hanna KR, Lewis JE, Neubauer BL \& GraffJR 2005 The progression of LNCaP human prostate cancer cells to androgen independence involves decreased FOXO3a expression and reduced p27KIP1 promoter transactivation. Molecular Cancer Research 3 163-169. (doi:10.1158/1541-7786.MCR-04-0163)

Lynch VJ, Brayer K, Gellersen B \& Wagner GP 2009 HoxA-11 and FOXO1A cooperate to regulate decidual prolactin expression: towards inferring the core transcriptional regulators of decidual genes. PLoS ONE 4 e6845. (doi:10.1371/journal.pone.0006845)

Ma Q, Fu W, Li P, Nicosia SV, Jenster G, Zhang X \& Bai W 2009 FoxO1 mediates PTEN suppression of androgen receptor $\mathrm{N}$ - and C-terminal interactions and coactivator recruitment. Molecular Endocrinology 23 213-225. (doi:10.1210/me.2008-0147)

Maiese K, Chong ZZ \& Shang YC 2008a OutFOXOing disease and disability: the therapeutic potential of targeting FoxO proteins. Trends in Molecular Medicine 14 219-227. (doi:10.1016/j.molmed.2008.03.002)

Maiese K, Chong ZZ, Shang YC \& Hou J 2008b A "FOXO" in sight: targeting Foxo proteins from conception to cancer. Medicinal Research Reviews 29 395-418. (doi:10.1002/med.20139)

Mak IY, Brosens JJ, Christian M, Hills FA, Chamley L, Regan L \& White JO 2002 Regulated expression of signal transducer and activator of transcription, Stat5, and its enhancement of PRL expression in human endometrial stromal cells in vitro. Journal of Clinical Endocrinology and Metabolism 87 2581-2588. (doi:10.1210/jc.87.6.2581)

Matsumoto M, Han S, Kitamura T \& Accili D 2006 Dual role of transcription factor FoxO1 in controlling hepatic insulin sensitivity and lipid metabolism. Journal of Clinical Investigation 116 2464-2472. (doi:10.1172/JCI27047)

Matsuzaki H, Daitoku H, Hatta M, Aoyama H, Yoshimochi K \& Fukamizu A 2005 Acetylation of Foxo1 alters its DNA-binding ability and sensitivity to phosphorylation. PNAS 102 11278-11283. (doi:10.1073/pnas. 0502738102) 
Maxwell GL, Risinger JI, Gumbs C, Shaw H, Bentley RC, Barrett JC, Berchuck A \& Futreal PA 1998a Mutation of the PTEN tumor suppressor gene in endometrial hyperplasias. Cancer Research 58 2500-2503.

Maxwell GL, Risinger JI, Tong B, Shaw H, Barrett JC, Berchuck A \& Futreal PA 1998b Mutation of the PTEN tumor suppressor gene is not a feature of ovarian cancers. Gynecologic Oncology 70 13-16. (doi:10.1006/ gyno.1998.5039)

McDonald SE, Henderson TA, Gomez-Sanchez CE, Critchley HO \& Mason JI 2006 11Beta-hydroxysteroid dehydrogenases in human endometrium. Molecular and Cellular Endocrinology 248 72-78. (doi:10. 1016/j.mce.2005.12.010)

Miranda KC, Huynh T, Tay Y, Ang YS, Tam WL, Thomson AM, Lim B \& Rigoutsos I 2006 A pattern-based method for the identification of microRNA binding sites and their corresponding heteroduplexes. Cell 126 1203-1217. (doi:10.1016/j.cell.2006.07.031)

Mishima T, Takizawa T, Luo SS, Ishibashi O, Kawahigashi Y, Mizuguchi Y, Ishikawa T, Mori M, Kanda T, Goto T et al. 2008 MicroRNA (miRNA) cloning analysis reveals sex differences in miRNA expression profiles between adult mouse testis and ovary. Reproduction 136 811-822. (doi:10.1530/REP-08-0349)

Morelli C, Lanzino M, Garofalo C, Maris P, Brunelli E, Casaburi I, Catalano S, Bruno R, Sisci D \& Ando S 2010 Akt2 inhibition enables the forkhead transcription factor FoxO3a to have a repressive role in estrogen receptor alpha transcriptional activity in breast cancer cells. Molecular and Cellular Biology 30 857-870. (doi:10.1128/MCB.00824-09)

Myatt SS \& Lam EW 2007 The emerging roles of forkhead box (Fox) proteins in cancer. Nature Reviews. Cancer 7 847-859. (doi:10.1038/nrc2223)

Myatt SS, Wang J, Monteiro LJ, Christian M, Ho KK, Fusi L, Dina RE, Brosens JJ, Ghaem-Maghami S \& Lam EW 2010 Definition of microRNAs that repress expression of the tumor suppressor gene FOXO1 in endometrial cancer. Cancer Research 70 367-377. (doi:10.1158/0008-5472. CAN-09-1891)

Nuovo GJ 2010 In situ detection of microRNAs in paraffin embedded, formalin fixed tissues and the co-localization of their putative targets. Methods 52 307-315. (doi:10.1016/j.ymeth.2010.08.009)

Paik JH, Kollipara R, Chu G, Ji H, Xiao Y, Ding Z, Miao L, Tothova Z, Horner JW, Carrasco DR et al. 2007 FoxOs are lineage-restricted redundant tumor suppressors and regulate endothelial cell homeostasis. Cell 128 309-323. (doi:10.1016/j.cell.2006.12.029)

Pan Q, Luo X, Toloubeydokhti T \& Chegini N 2007 The expression profile of micro-RNA in endometrium and endometriosis and the influence of ovarian steroids on their expression. Molecular Human Reproduction 13 797-806. (doi:10.1093/molehr/gam063)

Pandey DP \& Picard D 2009 miR-22 inhibits estrogen signaling by directly targeting the estrogen receptor alpha mRNA. Molecular and Cellular Biology 29 3783-3790. (doi:10.1128/MCB.01875-08)

Pandey DP \& Picard D 2010 Multidirectional interplay between nuclear receptors and microRNAs. Current Opinion in Pharmacology 10 637-642. (doi:10.1016/j.coph.2010.08.009)

Parkin DM, Bray F, Ferlay J \& Pisani P 2005 Global cancer statistics, 2002. CA: A Cancer Journal for Clinicians 55 74-108. (doi:10.3322/canjclin. 55.2.74)

Plas DR \& Thompson CB 2003 Akt activation promotes degradation of tuberin and FOXO3a via the proteasome. Journal of Biological Chemistry 278 12361-12366. (doi:10.1074/jbc.M213069200)

Pohnke Y, Schneider-Merck T, Fahnenstich J, Kempf R, Christian M, Milde-Langosch K, Brosens JJ \& Gellersen B 2004 Wild-type p53 protein is up-regulated upon cyclic adenosine monophosphate-induced differentiation of human endometrial stromal cells. Journal of Clinical Endocrinology and Metabolism 89 5233-5244. (doi:10.1210/jc.2004-0012)

Puig O, Marr MT, Ruhf ML \& Tjian R 2003 Control of cell number by Drosophila FOXO: downstream and feedback regulation of the insulin receptor pathway. Genes and Development 17 2006-2020. (doi:10.1101/gad. 1098703)

Qian K, Hu L, Chen H, Li H, Liu N, Li Y, Ai J, Zhu G, Tang Z \& Zhang H 2009 Hsa-miR-222 is involved in differentiation of endometrial stromal cells in vitro. Endocrinology 150 4734-4743. (doi:10.1210/en.2008-1629)
Ratner ES, Tuck D, Richter C, Nallur S, Patel RM, Schultz V, Hui P, Schwartz PE, Rutherford TJ \& Weidhaas JB 2010 MicroRNA signatures differentiate uterine cancer tumor subtypes. Gynecologic Oncology 118 251-257. (doi:10.1016/j.ygyno.2010.05.010)

Reedquist KA, Ludikhuize J \& Tak PP 2006 Phosphoinositide 3-kinase signalling and FoxO transcription factors in rheumatoid arthritis. Biochemical Society Transactions 34 727-730. (doi:10.1042/BST0340727)

Rena G, Woods YL, Prescott AR, Peggie M, Unterman TG, Williams MR \& Cohen P 2002 Two novel phosphorylation sites on FKHR that are critical for its nuclear exclusion. EMBO Journal 21 2263-2271. (doi:10.1093/ emboj/21.9.2263)

Resnick KE, Alder H, Hagan JP, Richardson DL, Croce CM \& Cohn DE 2009 The detection of differentially expressed microRNAs from the serum of ovarian cancer patients using a novel real-time PCR platform. Gynecologic Oncology 112 55-59. (doi:10.1016/j.ygyno.2008.08.036)

Risinger JI, Hayes K, Maxwell GL, Carney ME, Dodge RK, Barrett JC \& Berchuck A 1998 PTEN mutation in endometrial cancers is associated with favorable clinical and pathologic characteristics. Clinical Cancer Research 4 3005-3010.

Ro S, Song R, Park C, Zheng H, Sanders KM \& Yan W 2007 Cloning and expression profiling of small RNAs expressed in the mouse ovary. RNA 13 2366-2380. (doi:10.1261/rna.754207)

Schuster C, Budczies J, Faber C, Kirchner T \& Hlubek F 2010 MicroRNA expression profiling of specific cells in complex archival tissue stained by immunohistochemistry. Laboratory Investigation 91 157-165. (doi:10.1038/ labinvest.2010.134)

Schwarz DS, Hutvagner G, Du T, Xu Z, Aronin N \& Zamore PD 2003 Asymmetry in the assembly of the RNAi enzyme complex. Cell 115 199-208. (doi:10.1016/S0092-8674(03)00759-1)

Sekiya T, Adachi S, Kohu K, Yamada T, Higuchi O, Furukawa Y, Nakamura Y, Nakamura T, Tashiro K, Kuhara S et al. 2004 Identification of BMP and activin membrane-bound inhibitor (BAMBI), an inhibitor of transforming growth factor-beta signaling, as a target of the beta-catenin pathway in colorectal tumor cells. Journal of Biological Chemistry 279 6840-6846. (doi:10.1074/jbc.M310876200)

Seoane J, Le HV, Shen L, Anderson SA \& Massague J 2004 Integration of Smad and forkhead pathways in the control of neuroepithelial and glioblastoma cell proliferation. Cell 117 211-223. (doi:10.1016/S00928674(04)00298-3)

Shimizu Y, Takeuchi T, Mita S, Notsu T, Mizuguchi K \& Kyo S 2010 Kruppel-like factor 4 mediates anti-proliferative effects of progesterone with G0/G1 arrest in human endometrial epithelial cells. Journal of Endocrinological Investigation 33 745-750. (doi:10.3275/7044)

Sirotkin AV, Ovcharenko D, Grossmann R, Laukova M \& Mlyncek M 2009 Identification of microRNAs controlling human ovarian cell steroidogenesis via a genome-scale screen. Journal of Cellular Physiology 219 415-420. (doi:10.1002/jcp.21689)

Szafranska AE, Davison TS, Shingara J, Doleshal M, Riggenbach JA, Morrison CD, Jewell S \& Labourier E 2008 Accurate molecular characterization of formalin-fixed, paraffin-embedded tissues by microRNA expression profiling. Journal of Molecular Diagnostics 10 415-423. (doi:10.2353/jmoldx.2008.080018)

Takano M, Lu Z, Goto T, Fusi L, Higham J, Francis J, Withey A, Hardt J, Cloke B, Stavropoulou AV et al. 2007 Transcriptional cross talk between the forkhead transcription factor forkhead box O1A and the progesterone receptor coordinates cell cycle regulation and differentiation in human endometrial stromal cells. Molecular Endocrinology 21 2334-2349. (doi:10.1210/me.2007-0058)

Tam W 2008 The emergent role of microRNAs in molecular diagnostics of cancer. Journal of Molecular Diagnostics 10 411-414. (doi:10.2353/jmoldx. 2008.080067)

Tanzer A \& Stadler PF 2004 Molecular evolution of a microRNA cluster. Journal of Molecular Biology 339 327-335. (doi:10.1016/j.jmb.2004.03.065)

Teague EM, Print CG \& Hull ML 2010 The role of microRNAs in endometriosis and associated reproductive conditions. Human Reproduction Update 16 142-165. (doi:10.1093/humupd/dmp034) 
Trujillo RD, Yue SB, Tang Y, O'Gorman WE \& Chen CZ 2010 The potential functions of primary microRNAs in target recognition and repression. EMBO Journal 29 3272-3285. (doi:10.1038/emboj.2010.208)

Vogt PK, Jiang H \& Aoki M 2005 Triple layer control: phosphorylation, acetylation and ubiquitination of FOXO proteins. Cell Cycle $\mathbf{4}$ 908-913. (doi:10.4161/cc.4.7.1796)

Woods YL, Rena G, Morrice N, Barthel A, Becker W, Guo S, Unterman TG \& Cohen P 2001 The kinase DYRK1A phosphorylates the transcription factor FKHR at Ser329 in vitro, a novel in vivo phosphorylation site. Biochemical Journal 355 597-607.

Wu W, Lin Z, Zhuang Z \& Liang X 2009 Expression profile of mammalian microRNAs in endometrioid adenocarcinoma. European Journal of Cancer Prevention 18 50-55. (doi:10.1097/CEJ.0b013e328305a07a)

Yamagata K, Fujiyama S, Ito S, Ueda T, Murata T, Naitou M, Takeyama K, Minami Y, O'Malley BW \& Kato S 2009 Maturation of microRNA is hormonally regulated by a nuclear receptor. Molecular Cell 36 340-347. (doi:10.1016/j.molcel.2009.08.017)

Yang JY \& Hung MC 2009 A new fork for clinical application: targeting forkhead transcription factors in cancer. Clinical Cancer Research $\mathbf{1 5}$ 752-757. (doi:10.1158/1078-0432.CCR-08-0124)
Yang JY, Zong CS, Xia W, Yamaguchi H, Ding Q, Xie X, Lang JY, Lai CC, Chang CJ, Huang WC et al. 2008 ERK promotes tumorigenesis by inhibiting FOXO3a via MDM2-mediated degradation. Nature Cell Biology 10 138-148. (doi:10.1038/ncb1676)

Yao N, Lu CL, Zhao JJ, Xia HF, Sun DG, Shi XQ, Wang C, Li D, Cui Y \& Ma X 2009 A network of miRNAs expressed in the ovary are regulated by FSH. Frontiers in Bioscience 14 3239-3245. (doi:10.2741/3447)

Ying SY \& Lin SL 2006 Current perspectives in intronic micro RNAs (miRNAs). Journal of Biomedical Science 13 5-15. (doi:10.1007/s11373-005-9036-8)

Zou Y, Tsai WB, Cheng CJ, Hsu C, Chung YM, Li PC, Lin SH \& Hu MC 2008 Forkhead box transcription factor FOXO3a suppresses estrogendependent breast cancer cell proliferation and tumorigenesis. Breast Cancer Research 10 R21. (doi:10.1186/bcr1872)

Received in final form 25 January 2011

Accepted 7 March 2011

Made available online as an Accepted Preprint

7 March 2011 